\title{
The Existing State of and Solution to Construction Cost
}

\author{
Zan Wenxiao \\ Engerneering Department of Yunnan College of Foreign Affairs \& Foreign Languages, Kunming, 651700 \\ 447217178@qq.com
}

\begin{abstract}
Construction engineering plays an important role in enhancing the economy growth of China and has made great contribution to its national economy. In this market-oriented mode of economy, cost management in the field of construction engineering draws more and more attention. Cost management helps to enhance the quality of construction engineering and facilitates capital flow and replenishment in construction corporations. And the construction project investment cost control theory based on the cost of domestic and international engineering and management theory, in summing up the cost of existing projects at home and abroad and established control methods and practical experience on the basis of the stage through cost management targets for cost-related factors,
\end{abstract}

bidding, making price lost control of the analysis of the reasons for proposed construction projects and determine the reasonable cost of effective control measures taken.

Keywords-Construction Engineering; Cost; Management; Situation; Countermeasures

Cost management serves as a basic part in engineering management. Cost management is essential throughout the engineering construction, including the final phase of the construction. Hence, it has always been a popular topic in the field of engineering to explore the existing state of and solution to construction cost.

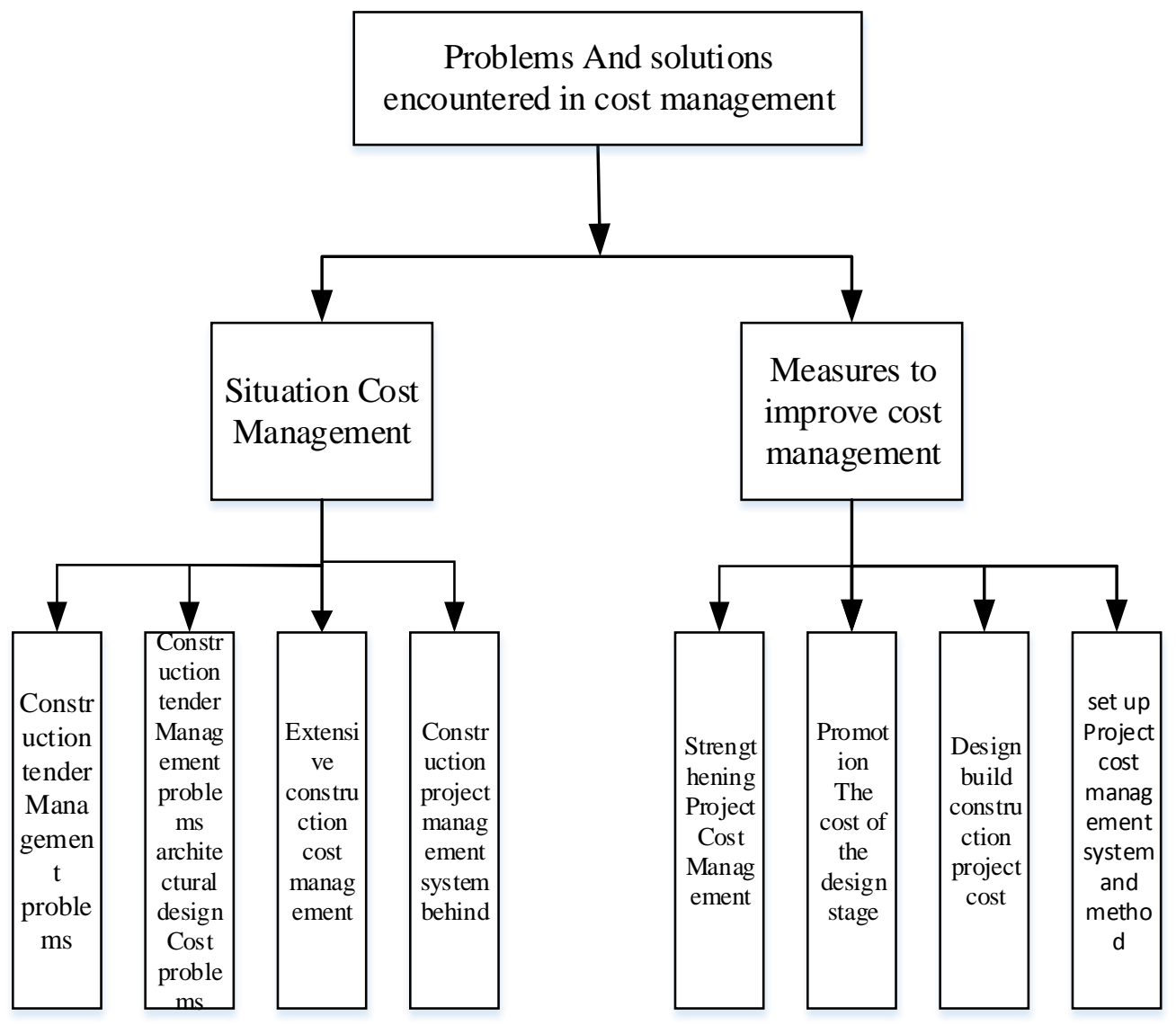

Figure 1. Construction Cost Management Problems and Solutions encounter 


\section{THE EXISTING STATE OF THE COST MANAGEMENT}

\section{IN CONSTRUCTION ENGINEERING}

Engineering cost management is an essential part in engineering construction. High quality cost management means, on one hand, the save of cost and the efficiency of corporation capital and on the other hand a kind of restraint to the corporations. This paper studies the existing state of cost management in engineering construction corporations from the following four aspects.

\section{A. Problem of cost management hidden in construction bidding}

To win the construction bidding, corporations tend to lower the bidding price. Yet the lower the price, the more hazards will occur in the process of carrying out the construction. In case of a low construction bidding price, the construction party will get less amount of construction capital for the engineering construction. That is to say, the lower quotation for construction cost will result in the lack of construction capital and as a result may cause jerry-build in the process of construction. Therefore, as far as the construction cost issue in construction bidding is concerned, a low price for the cost in the bidding phase will affect the construction that follows up and usually put the construction quality in jeopardy.

\section{B. Problem of cost management hidden in construction design}

Problem of cost management may also occur in the phase of construction design. In this phase, designers usually focus on the construction design and arrangement, and attach less importance to construction cost. However, issues concerned with construction cost may also cause an effect on the whole construction. Considering the particulars in the current construction management and construction design, the management of construction cost in the phase of construction design is still not enough. Construction cost has not been given enough attention; proper scheme for construction cost has not been worked out, which will cause trouble in construction cost management.

\section{Extensive mode of construction cost management in construction work phase}

In construction work, construction cost management is essential throughout the whole cost management process. Construction work concerns with the direct use of the construction fund, so the construction cost in this phase plays a decisive role in the wellbeing of the whole construction cost. Currently, the characteristics of construction cost management are clearly free and extensive. In the construction work phase, there is no clear and accurate record of how the capital budget is worked out and how the fund is spent. Moreover, many constriction corporations still adopt the old-fashioned mode of cost management. As the cost management work in construction engineering varies with the development of society, traditional way of cost management can't meet the demand of the construction cost management in the new society. Therefore, this old-fashioned way of cost management to a great extent is to the detriment of the construction cost management.

\section{Old-fashioned system of construction cost management}

In practice, the system of construction cost management is rather old-fashioned. The management method has not yet been information-dominated. This very practice is in the way of the conduct of construction cost management.

At present, in many architectural construction corporations, directors of construction cost fail to attach proportional importance to construction cost work. The cost management system is still imperfect in most corporations. There comes the management predicament in carrying out and fulfilling the specific cost management work. In addition, as we above mentioned, the management method lags behind. In modern society, information-related technology finds its application almost in every field. Yet the technology has not been fully adopted in construction cost work.

\section{SOLUTION TO PERFECT CONSTRUCTION COST MANAGEMENT}

Construction cost management has always been critical to the fulfillment of the architectural construction. To ensure a satisfactory construction cost management, different methods shall be adopted in accordance with the construction phases.

\section{A. Enhance construction cost management in biding phase}

In the case of a rather low construction quotation, the director shall in bidding phase strengthen supervision of the construction, especially those of cost management and quotation management. For instance, in the case of a rather low quotation, the director can regulate the quotation to a reasonable level. In this way, the director can monitor the whole construction cost work from the biding phase. Moreover, reinforcing construction cost management in the bidding phase calls for upgrading the cost monitor of construction bidding work. In the cost analysis of construction bidding, problems in the cost management shall be given extra attention, and supervision in the biding phase shall be more strict and precise to perfect the construction monitor on the whole.

\section{B. Enhance construction cost management in construction design phase}

In the construction design phase, the designer shall pay attention to the cost management design and devote to improve the construction cost management. To do a better job in cost design, the director can measure and evaluate the construction design arrangement through the design terminal. In particular, the construction design scheme can be used as the guidance in the design work. Cost work is related to every procedure in the construction. As the cost director, he should analyze the construction budget in accordance with the objective of the construction cost management, and thereafter explore and study the cost problem found in the design phase. In addition, the director shall also regulate the capital efficiency in the construction design phase. Only by using the capital in a rational and efficient way can the cost capital for the construction be employed effectively in a whole. 


\section{Set up detailed construction cost design}

In the execution of construction cost, extensive mode of construction cost management shall be promoted into a detailed mode of management. As the more detailed the construction cost, the more efficient the construction cost fund, detailed mode of management will promote the whole construction management and operation.

To come up with a detailed design standard for construction cost, the cost personnel should on one hand analyze problems in internal cost management and on the other hand give a sound cost design method. A sound design standard for cost management will generate more precise management objective. In addition, in the construction cost management work, the director should set up concise cost objective to increase the general level and potentiality of cost management, which in turn will strengthen the objective of the cost management. In the cost management work, detailed mode of cost management requires the support of well-round cost management system. So in the engineering system, the manager shall focus on setting up concise cost management system and method particularly to facilitate the construction cost work on a whole.

\section{Set up and perfect the construction cost management system and method}

In the whole construction cost management work, the corporations shall attach great importance to the enhancement of the construction cost management work level. They should also devote themselves to guarantee that the cost manager has a better understanding of the cost management work, improve their work ability in cost management, perfect the cost management system, and pay enough attention to the cost monitor. Moreover, in the management of cost work, information technology shall be adopted in the cost management work, higher level information technology shall be pursued, and cost management system shall be fully developed to better push forward the cost management work.

\section{CONCLUSION}

The construction cost management work is closely connected with the efficiency of the whole construction as well as the construction quality. In the future, the manager shall focus on improving the management level of the engineering construction cost, and devote to perfect the cost management scheme from many aspects to ensure the wellbeing of the engineering construction.

\section{REFERENCE}

[1] Wei Guimei. Analysis on how to Enhance Construction Cost Management [J]. China New Technology New Product, 2013,(13).

[2] Wang Xin. Study on Several Issues in Construction Cost Management $[\mathrm{J}]$. Construction Materials and Decoration (Later Part of a Month), 2012, (12).

[3] Bo Gnan, Changjun Shu. Development of Urban Agriculture: A Case Study of Qian jin village, Jiangxia District, Wuhan City [J].Asian Agricultural Research, 2012, 4 (2): 18-20.

[4] Jun Fang, Changjun Shu. Research on The General Contractor Enterprise Collaborative Management System Based on Web Services. 16th International Symposium on Advancement of Construction Management and Real Estate (CRIOCM 2011), Chongqing, China, 2011,463-466

[5] Hammad Ud Din Tahir. Effective Planning Techniques for the Execution of an EPC Project[J].Insect Mol Biol, 2012,146-149.

[6] Wood, Bevyn, Kenley, Russel .The effectiveness of the bills of quantities in Australia. Journal of Construction Research, 2014,5(9):291-309.

[7] Mohamed, KA et al. Contuactor's decision for bid profit reduction within opportunistic bidding beharior of claims recovery[J]. project Manage, 2009(12):1-15.

[8]J Guthrie. The management, measurement and the reporting of intellectual capital [J].Journal of Intellectual Capital, 2003(1):27-41.

[9] J. M. Smith. Multi base integrating heterogeneous distributed database systems' in proceedings of the national computer conference[J]. AFIPS press, Montvale,NJ, 1981:487-499.

[10] Jun Fang, Changjun Shu. A Cross-platform integration design of the construction cost information resources in projects. 2011 International Conference on Electric Technology and Civil Engineering, Lushan, China, 2011,IEEE, 5689-5693 